\title{
Transposon Reactivation in the Germline May Be Useful for Both Transposons and Their Host Genomes
}

\author{
Stéphanie Maupetit-Mehouas * and Chantal Vaury *(1) \\ GReD Institute, Université Clermont Auvergne, CNRS, Inserm, Faculté de Médecine, CRBC, 28 place Henri \\ Dunant, TSA 50400, CEDEX 1, 63001 Clermont-Ferrand, France \\ * Correspondence: stephanie.maupetit_mehouas@uca.fr (S.M.-M.); chantal.vaury@uca.fr (C.V.)
}

Received: 27 April 2020; Accepted: 7 May 2020; Published: 8 May 2020

\begin{abstract}
Transposable elements (TEs) are long-term residents of eukaryotic genomes that make up a large portion of these genomes. They can be considered as perfectly fine members of genomes replicating with resident genes and being transmitted vertically to the next generation. However, unlike regular genes, TEs have the ability to send new copies to new sites. As such, they have been considered as parasitic members ensuring their own replication. In another view, TEs may also be considered as symbiotic sequences providing shared benefits after mutualistic interactions with their host genome. In this review, we recall the relationship between TEs and their host genome and discuss why transient relaxation of TE silencing within specific developmental windows may be useful for both.
\end{abstract}

Keywords: retroelements; transposable elements; piRNAs; DNA methylation; KRAB complex; silencing; germline; DRTS; Pilp

\section{Introduction}

Transposable elements (TEs) are genomic sequences having the ability to move from one location to another on the genome. They make up a large portion of eukaryotic genomes, as in Human where they account for almost $50 \%$ of the genome. The presence of TEs within genomes is dynamic. TEs tend to accumulate mutations and deletions leading the progressive extinction of the whole family in a species. Nonetheless, the reason TEs are widespread and persist in genomes is explained by the fact that at least some TEs remain active and have the capacity to regularly invade new species through horizontal transfers [1-4]. So, genomes display old, mostly inactive copies of TEs together with recent and mostly active copies of some families. TEs have long been considered as mutagenic agents that can generate insertional mutagenesis and chromosomal breaks upon mobilizations [5-7]. A long-lasting question has arisen so as to understand why old TE copies still persist in genomes if they are inactive. This is attributed to mutualistic interactions with their host resulting in shared benefit. On the one hand, TEs have been reported as evolutionary forces that shaped mammalian genomes. As a single and recent example, when exploring the evolutionary forces that shaped Muridae and Hominidae genomes, Thybert et al. showed that the ongoing expansion of the long interspersed nuclear element (LINE) retrotransposons appears to be associated with some gene cluster expansions in the different Muridae genomes [1]. Their data also suggest a model in which these repeats could have increased the susceptibility to rearrangements via nonallelic homologous recombination.

On the other hand, the host organism may take benefit of sudden remodeled regulatory programs due to TE integrations providing new enhancers, alternative promoters, or creating new exons that may add useful functions to the gene product [8-11]. Importantly, domestication of coding sequences of retrotransposons may create new genes. An iconic example is the independent capture of Env genes from Endogenous RetroViruses (ERV), called syncytins, useful for placentation [12]. During the last 
decade, studies able to estimate the global impact of TEs on gene regulatory networks have gained a lot with genome sequencing projects, the development of new bioinformatic tools, and whole-genome functional assays [13-15].

Beside the potential value of de novo integrations, the fact remains that TE amplification significantly contributes to genetic disease $[16,17]$. Conflict between TEs and their host genomes is then a critical factor limiting TE spreading. The genome has evolved sophisticated mechanisms to control TE mobilization. On their side, TEs have evolved a counter defense to escape from this host defense or limit its efficiency. This antagonistic host-TE coevolution is known as an arms race leading to a reciprocal adaptation [18-20].

In this review, we report the main mechanisms used by the host to restrain TE amplification and discuss developmental windows described in mice, drosophila, and plant reproductive tissues during which TE silencing is weakened allowing a transient TE transcription.

\section{Genome Defense Plays a Crucial Role in Limiting TE Proliferation}

Host genomes have developed mechanisms that reduce the cost of TE transposition, specifically in the germline where transposition has to occur to propagate within the population. These repressions occur both at the transcriptional (TGS) and post-transcriptional level (PTGS). This review is not intended to be a comprehensive review of these repressions, but rather a sampling of findings that have shed light on TE silencing and occasional desilencing in reproductive tissues. Such repressions employ DNA methylation, chromatin modifications including sequence specific transcriptional repression by Krüppel-associated box (KRAB) complexes, and small RNAs.

\subsection{DNA Methylation}

Cytosine DNA methylation is the main DNA methylation studied so far. It occurs mostly on the fifth carbon of cytosines (5-methylcytosine $(5 \mathrm{mC})$ ) of symmetrical CpG dinucleotides. This DNA modification is widespread from bacteria to mammals but absent in some eukaryotes like Drosophila melanogaster, Caenorhabditis elegans, or fission yeast. During mammalian gametogenesis, DNA methyltransferases encoded by the Dnmt3A and Dnmt3B genes, and their catalytically inactive cofactor DNMT3L, mediate cytosine methylation of TEs. Dnmt3L-/- germ cells present a low level of methylation associated with a high TE expression [21]. Surprisingly, germ-cell-specific mutants of Dnmt3B have no effect on fertility, while Dnmt3A mutants are infertile with mild changes in TE methylation. DNMT3A and $3 \mathrm{~B}$ are known as de novo DNMT, able to methylate hemi-methylated and unmethylated CpG. By contrast, the DNA methyl transferase called DNMT1 functions during DNA replication to copy the DNA methylation pattern from the parental DNA strand to the newly synthesized strand. Contrasting with Dnmt3A-/-, 3B-/-, a massive demethylation and derepression of the evolutionary young retrotransposons Intracisternal A particles (IAP) is observed in Dnmt1-null mutant Embryonic Stem Cells (ESCs) [22].

Another DNMT, DNMT3C, has been recently identified in mouse as a DNA methyltransferase specific to retrotransposons [23]. The Dnmt3C gene, which had been considered as a pseudogene, was revealed to originate from the duplication of Dnmt3B in the Muroidea lineage [22,24]. Dnmt3C expression is specific to male fetal germ cells and selectively methylates and represses the promoters of evolutionarily young transposable elements. How the Human genome lacks Dnmt3C copies with TEs is still an open question, but recent evolutionary analyses suggest that DNMT3A might be the enzyme carrying this function [25].

These DNMT studies converge on the notion that methylation targeting TEs limits TE transposition. In support of this, demethylating drugs activate TE transcription and unmethylated human L1 elements transpose at a higher rate in transfected cells than methylated L1 [23]. Moreover, cytosine DNA methylation has been proposed to limit the threats posed by genomic rearrangements due to recombination occurring between these dispersed homologous sequences. Methylation would restrain transposons from adopting a chromatin signature permissive for meiotic recombination [26]. Indeed, 
an increase of chromosomal rearrangements in human cancers is correlated with hypomethylation. Overall, Cytosine DNA methylation is reported as a key epigenetic modification required for gene regulation and is considered a host-control counteracting the threat of TEs [27]. As mammalian TE promoters are $\mathrm{CpG}$ rich, it has even been suggested that CG methylation has evolved for the specific purpose of defending the host genome against TE activity [27-29].

\subsection{Sequence-Specific Transcriptional Repressors}

Many studies have shown a clear correlation between Cytosine DNA methylation and the transcriptional inactive state of TEs. However, very little is known about how TEs are specifically targeted. Studies on the Krüppel-associated box (KRAB) domain containing zinc-finger proteins (KRAB-ZFPs) have brought some understanding.

KRAB-ZFPs are a rapidly evolving gene family, the root of which has been recently reported in a common ancestor of coelacanths and tetrapods [30]. KRAB-ZFPs are DNA binding factors containing an $\mathrm{N}$-terminal KRAB domain followed by a variable array of $\mathrm{C} 2 \mathrm{H} 2$-type zinc fingers [31,32]. Acting as transcriptional repressors, KRAB-ZFPs bind to DNA through their zinc finger domain. Via the KRAB domain, they recruit the corepressor KAP1 (also called TRIM28) which subsequently recruits epigenetic modifiers such as histone modifiers and DNA methyltransferases [33,34].

Characterization of KRAB-ZFP genomic targets has pointed out that many of them target and silence TEs. Most of our current knowledge comes from studies performed at very early stages of mammal development and in ESCs in which it was found that a large majority of KRAB-ZFPs associate with at least one subfamily of TEs. In mouse ESC, the Zinc Finger Protein ZFP809 targets TRIM28 to the primer binding site sequences (PBS) which are bound by specific tRNAs to prime MLVs and ERVs reverse transcription [34,35]. ZFP809 is then recognized as a stem-cell specific factor, targeting to silence a large subset of retroviruses and retrotransposons and participating in the intrinsic immune system of stem cells. The recruitment of KRAB-ZFPs may also occur to specific TE promoters or 3' ends or be influenced by the age of the TE. In human embryonic stem cells (hES), KAP1 (TRIM28) represses a discrete subset of LINE1 (L1) elements corresponding to L1 having invaded the ancestral genome several millions of year ago [36]. If KAP1 is knocked down in these cells, the expression of KAP1-bound L1 elements is induced, whereas the younger copies of these Human L1 are unaffected.

KRAB-ZFPs and TEs are thought to be locked in an evolutionary arms race, with new KRAB-ZFPs continuously emerging to cope with newly invading TEs [36]. This has been deduced from studies performed in a wide range of vertebrate species and reporting that the copy number of KRAB-ZFPs in these genomes correlates with the amount of LTR retroelements [37]. When investigating the evolutionary emergence of KRAB-ZFP genes in vertebrates and identifying their targets in the human genome, Imbeault and Trono found that many TEs whose activity has been lost for a long time since they invaded the genomes are still bound by KRAB-ZFP, suggesting that the arms race has not been the sole driver of selection and maintenance of KRAB-ZFP genes in mouse and human [30]. The data rather point out a domestication model in which some KRAB-ZFP co-opt TEs for the benefit of the host and may build a species-restricted layer of epigenetic regulation [28].

\subsection{Transcriptional and Post-Transcriptional Silencing Mediated by Small RNAs}

Small interfering RNAs accomplish silencing of genes targeted through RNA-RNA base pairing. In gonads, the major small RNA pathway involved in TE silencing is the PIWI-interacting RNA (piRNA) pathway. piRNAs are single strand RNAs of 23 to 32 nucleotides long that assemble in piRNA-induced silencing complexes (piRISCs) with PIWI proteins [38]. Cytoplasmic PIWI proteins are small RNA-guided nucleases that guide endonucleolytic cleavage of TE mRNAs. Nuclear PIWI proteins assemble silencing complexes on target genomic loci to mediate transcriptional silencing [39]. The piRNA-mediated silencing is active in the gonads of many species, including human, and has been discovered in Drosophila and mice in which the key steps of this mechanism have been elucidated. Regardless of which species, mutations affecting the pathway result in genome instabilities and 
sterility. In Drosophila, transcription of transposon rich loci called piRNA clusters, mostly located in pericentromeric regions, gives rise to long, single strand RNA precursors which are processed into piRNAs $[40,41]$. In the germline, piRNA clusters are mainly dual strand. Their transcription, including initiation and suppression of termination, requires the RDC complex made of Rhino (Rhi), Deadlock (Del), and Cutoff (Cuff) [42,43]. This complex recruits proteins required for transcription initiation within heterochromatin [44]. Rhino, Deadlock, and a recently identified gene CG13741/Bootlegger will then target the nuclear export factor 3 (Nxf3) to nascent piRNA precursors. After Cargo binding, Nxf3 achieves nuclear export of the unprocessed precursor transcripts. When in the cytoplasm, precursor transcripts accumulate in perinuclear nuage where piRNA processing occurs [45].

In the germline, piRNAs are amplified through a feed-forward RNA cleavage known as the ping-pong cycle [40]. This cleavage targets transcripts produced from both TEs and piRNA loci. It is achieved in the cytoplasm by the two PIWI proteins, AGO3 and Aub. TE transcripts being piRNA substrates of the ping-pong cycle, AGO3 and Aub are then actors of the post-transcriptional silencing of TEs. piRNAs amplified through the ping-pong cycle display specific signatures. When they are antisense to TE mRNAs, their $5^{\prime}$ end is rich in uridine (1U). When they are sense to TE mRNAs, they show an adenine bias at the 10th position (10A). The third PIWI protein identified in Drosophila, Piwi, is nuclear and accomplishes piRNA-mediated transcriptional silencing of TEs.

A similar piRNA amplification exists in mice. piRNAs act in complex with Argonaute proteins and silence TE expression by recognizing complementary RNAs. Disruption of the piRNA pathway in male mice leads to unsuppressed expression of certain TEs, which has been proposed to be at the origin of the sterility [46-48]. Most TE piRNAs originate from individual TE insertions and are amplified by the ping-pong cycle. Two groups of piRNAs can be distinguished according to the time of their expression during spermatogenesis (see below). In embryonic gonads, piRNAs resemble Drosophila piRNAs and silence TEs. Transposon silencing is then achieved thanks to MILI, a slicer-competent cytoplasmic Argonaute protein [47-49], and the nuclear MIWI2 proposed to recruit transcriptional silencing complexes over transcriptionally active TEs [50-52]. During the pachytene phase of meiotic prophase I, adult murine testes are highly enriched in piRNAs, but these piRNAs do not target TEs.

All these silencing pathways-DNA methylation, KRAB-ZFP epigenetic silencing, or small RNA targeting-act together to ensure TE silencing. Their multiple and complementary functions converge to repress all the families and each TE, be they old or recent genomic copies. They often mediate the deposition of similar chromatin modification, mostly histone tail modifications such as H3K9- and H4K20-trimethylation [53-55]. These mechanisms have been proposed to function in conjunction. Indeed, L1 elements are repressed even in the absence of both a functional piRNA pathway and DNA methylation in mitotic stages of spermatogenesis because of euchromatic repressive histone H3 dimethylated lysine 9 modifications cosuppressing L1 expression [56]. The network of silencing pathways may also work sequentially according to data reported by Castro-Diaz et al. Their data support a model in which new TEs would first be repressed by the DNA methylation-inducing small RNA-based mechanisms before KRAB-ZNP repressors are recruited [57].

\section{Windows of Vulnerability to Transposition in Germ Cells}

TEs have the possibility to occasionally evade the host controls. Indeed, several studies have reported that some TEs are highly expressed during short windows of germline development, a stage during which, paradoxically, TE control should be highly efficient to preserve genome integrity of the future organism and/or its progeny. These observations raise the possibility that replication cycles occur in these cells and lead to new genomic TE insertions. They also raise the possibility that TE transcripts produced at these specific stages play a cellular role during early development. Host genes and TEs might have a shared interest in such transient activations. 


\subsection{Resetting of Epigenetics Marks in Mammal Germ Cells}

As proposed by Molaro and Malik [24], what we consider as germ cells are cells that are able to transmit information to the progeny such as those that become gametes but also those of the early zygote and the inner cell mass of the blastocyst. Most of our knowledge concerning germ cell formation in mammals comes from mouse models. After fecundation of the mature oocyte by a spermatozoid, the paternal and maternal pronuclei will then be submitted to numerous molecular events leading to the acquisition of the zygote epigenome and to the Zygote Genome Activation (ZGA). The embryo develops to the blastocyst stage at around $3.5 \mathrm{dpc}$ (day post-coitum), and implants into the uterin mucosa. The embryo pursues its development and cell lineages differentiate to give rise to a newborn mouse at around $20 \mathrm{dpc}$.

Formation of germ cells happens quickly after implantation of the blastocyst ( $3.5 \mathrm{dpc})$ in the uterine mucosa. Some cells emanate from the proximal epiblast and are specified into primordial germ cells (PGCs). They proliferate - then migrate and colonize the genital ridge-the future gonads of either male or female (Figure 1). From PGCs, spermatozoids and oocytes will differentiate with obvious differences.

\section{A}

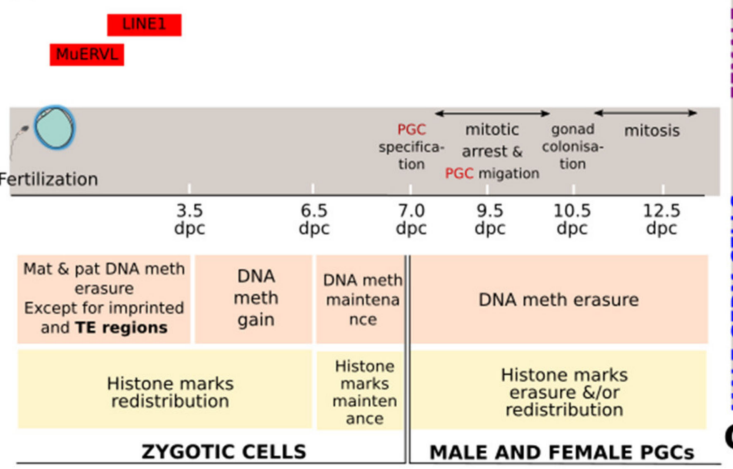

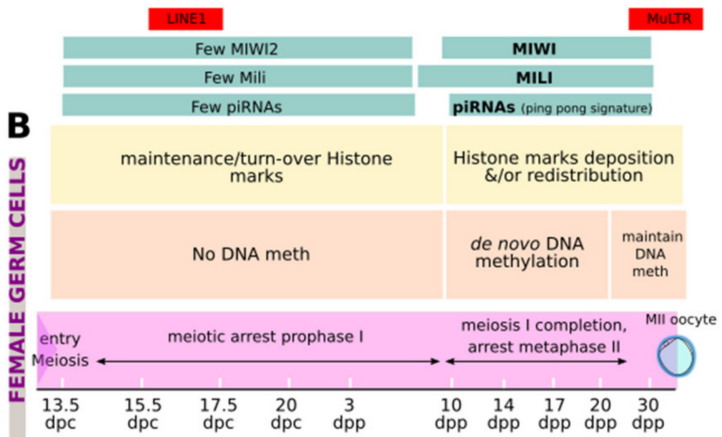

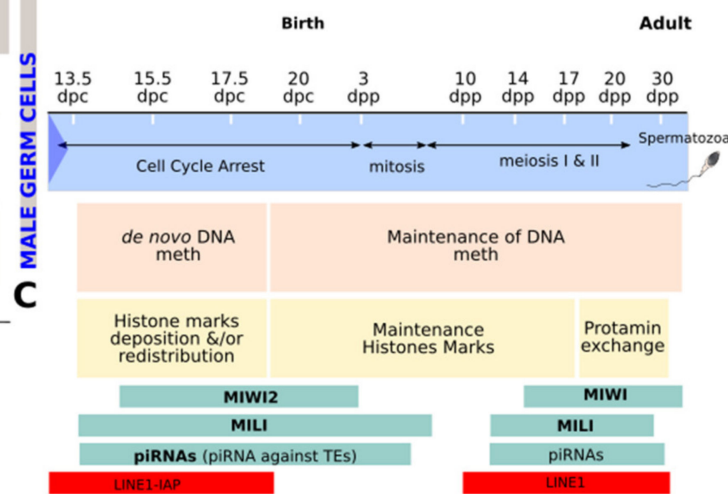

Figure 1. Schematic representation of transient transposable element (TE) relaxation during mouse germ cell development. From fertilization (A), maternal (mat) and paternal (pat) genomes undergo epigenetic reprogramming (DNA methylation (meth) resetting (orange) and chromatin remodeling (yellow)) that affects all genomic regions except imprinted regions and some TEs (red) until zygote implantation at 3.5 days post coïtum $(\mathrm{dpc})$. After implantation, a new epigenetic landscape is established in the zygote. From $6.5 \mathrm{dpc}$, some cells of the zygote are specified as primordial germ cells (PGCs) and migrate through the genital ridge, the precursor of the gonad. A massive epigenetic reprogramming affects these PGCs until they differentiate into either the female (B, pink rectangle) or male germ line (C, blue rectangle). During germ cell differentiation, expression of numerous TEs (red rectangles) is observed and associated with the epigenetic reprogramming (DNA methylation in orange and histone modification in yellow rectangles). Actors of the piRNA pathway are differently expressed during these stages (green rectangle). 
In males, germ cells are blocked in mitosis at around $13.5 \mathrm{dpc}$ until $3 \mathrm{dpp}$ (day post-partum) where they resume their mitotic proliferation to give rise to a large pool of spermatogonia. At $8 \mathrm{dpp}$, male germ cells initiate meiosis and differentiate to ultimately give rise to spermatozoa [58].

In females, germ cells initiate meiosis at $13.5 \mathrm{dpc}$ which is stopped at prophase I before birth. At $10 \mathrm{dpp}$, female germ cells pursue meiosis until a novel blockage at the metaphase II which gives rise to primary oocytes. The completion of meiosis of the mature oocyte will be achieved after fertilization by mature spermatozoids [58].

Two distinct global epigenetic reprogramming events take place within the germline that may affect the control of TEs. They occur after fertilization in all the zygotic cells during early embryo development at preimplantation stages, and in primordial germ cells of the developing embryo.

\subsubsection{Epigenetic Reprogramming during Early Embryo Development}

The first epigenetic reprogramming event begins just after fertilization, when the methylated paternal pronucleus is decondensed through the exchange of the protamine by maternal histones. This is accompanied by a rapid paternal DNA methylation erasure, through a putative active process, which is still debated. At this stage, the maternal pronucleus maintains its DNA methylation levels, but a widespread redistribution of histones marks seems to be initiated [59,60]. From the 2-Cells-stages (2C-stages), maternal and paternal DNA undergo a passive demethylation process which erases all gametic DNA methylation until the blastocyst stage $(3.5 \mathrm{dpc})$. Some genomic regions escape this loss of DNA methylation, including some TEs [61]. This specific DNA methylation maintenance and the hypothetic chromatin state may partly explain the absence of some TE desilencing during this developmental stage (Figure 1A).

Interestingly, specific de novo DNA methylation phases have been recently observed during this widespread DNA methylation erasure in human. Some genomic regions are specifically methylated including young and putatively active TEs (LINEs and SINEs). Actually, the molecular mechanism underlying this observation is not yet understood since this methylation is lost at later stages [62].

Nevertheless, this reprogramming step is a window of TE desilencing since almost $10 \%$ of the transcriptome from 2C-stage to blastocyst comes from TE transcription [63,64]. These TE reactivations are required for a proper embryonic development. This is the case of MuERV TE, giving one of the first transcripts expressed at a high level after fertilization $(8 \mathrm{~h})$, whose inhibition leads to an arrest of development at 2C-stages and alters ZGA [65].

Relaxation of TE silencing has also been reported in embryonic stem cells (ESCs). ESCs are pluripotent stem cells derived from the inner cell mass of blastocyst, a preimplantation stage embryo. Studies performed in ESCs in culture have nicely highlighted the potential impact of TEs on the developing embryo. In ESCs, the retrotransposon LINE1 which is the most abundant TE, and is still active in humans, is highly transcribed. Percharde et al. showed that these abundant LINE1 RNAs are nuclear in mouse ESCs where they recruit Nucleolin and KAP1/TRIM28 to repress Dux, the master activator of a transcriptional program specific to 2C-embryo [66]. In addition, LINE1 RNAs mediate binding of Nucleolin and KAP1 to rDNA and promote rRNA synthesis and ESC self-renewal. Accordingly, their depletion inhibits ESC self-renewal and induces the transition to a 2C-state. In embryos, it causes persistence of 2C-state and impairs ZGA. Thus, the specific transcription of LINE1 during this spatiotemporal window of mouse development is one of the actors orchestrating self-renewal of embryonic stem cells. Percharde et al. also stressed the fact that the role of LINE1 RNAs as chromatin-associated RNA avoids potential LINE1 retrotransposition and its associated detrimental effect. It has been proposed that the repeated and fast evolving nature of LINE1 might add robustness and adaptability to the regulation of early development. The same observation is made in cultured embryo whose RNA interference against its transcript leads to an arrest of early embryonic development $[67,68]$. 


\subsubsection{Epigenetic Reprogramming in Primordial Germ Cells of the Developing Embryo}

Before sex specification, PGCs are subject to a global epigenetic remodeling characterized by a loss of CpG DNA methylation and remodeling of chromatin (Figure 1B,C). This epigenetic reprogramming leads to a complete "resetting" of the epigenetic memory arising from the parent and the establishment of sex-specific gametic identity. In mice, this reprogramming begins at the specification of the germ cells in male and female. As much as 70\% of total CpG is methylated in "specified germ cells" of the epiblast at $6.5 \mathrm{dpc}$, compared to only $7 \%$ at $13.5 \mathrm{dpc}[69,70]$. This kinetics of demethylation is dependent of the specific characteristics of genomic regions, the demethylation process being slower for imprinted regions and retrotransposons [70,71]. These drastic losses of methylation are associated with a global remodeling of the chromatin characterized by a global increase/redistribution of some histone marks (H3K9me3 and H3K27me3) and a loss of others (H3K9me2). When germ cells are clearly differentiated into male and female, epigenetic reprogramming is then sex specific.

When female specificities are examined, it appears that female germ cells present a very low level of DNA methylation when blocked at prophase I of meiosis at $13.5 \mathrm{dpc}$. This low methylation is conserved until $10 \mathrm{dpp}$, where de novo DNA methylation will occur progressively with oocyte growth during folliculogenesis (Figure 1B). All this phenomenon is accompanied by a global histone mark modification. It is important to note that despite this important global loss of methylation during embryonic germ cell formation, no transcriptional burst is observed for all TEs except for a burst of LINE1 transcription at $16.5 \mathrm{dpc}[70,72]$. The same observation has been highlighted in fetal human germ cells where LINE1 and Alu clade transcripts have been found. These data suggest that, except for some of them, a control of numerous TEs is still effective during these spatiotemporal windows of epigenetic reprogramming that might be due to a chromatin-based repression [73].

In fetal female germ cells, inactivation of the piRNA pathway has no remarkable phenotype (females are fertile) but, according to current studies, some derepression of TEs is observed [74]. This suggests that the piRNA pathway has an impact on TE control during these developmental steps, uncoupled to sterility.

Later, in mature mouse oocyte, transcripts of LTR class III retrotransposons (such as the mouse transcript (MT) subfamily of MaLRs transposons (MT-LTR)) are extremely abundant [75]. It has been proposed that this transcription might be associated with specific functions of these cells at a later stage of germline development, such as oocyte attrition $[49,50,76]$.

In male germ cells, de novo DNA methylation occurs quickly after $13.5 \mathrm{dpc}$ to reach more than $40 \%$ of methylation at $16.5 \mathrm{dpc}$ [70]. The level of methylation continues to rise during differentiation into mature sperm cells to reach around $90 \%$ [71]. Two waves of de novo methylation are observed during which some regions resist methylation. These regions mostly concern young TEs such as LINE1 and IAP elements. Histones are then replaced by protamines to induce a major chromatin compaction (Figure 1C). Transcriptomic studies have shown that numerous TE transcripts are upregulated during the formation of embryonic male germ cells. This expression decreases with the wave of DNA de novo methylation: $30 \%$ of all reads at $13.5 \mathrm{dpc}, 20 \%$ at $16.5 \mathrm{dpc}$, and less than $15 \%$ in mature sperm cells. Some studies report that LINE1 ORF1 is expressed during fetal germ cells formation between $12.5 \mathrm{dpc}$ and $16.5 \mathrm{dpc}$ but not before. It is then downregulated after birth in spermatogonia [70,71]. These observations highlight the link existing between the epigenetic reprogramming occurring in male germline and relaxation of TEs.

The piRNA pathway plays an important function in the regulation of TE expression during embryonic male germ cell formation. The first expressed PIWI protein is MILI from $12.5 \mathrm{dpc}$ to round spermatids, with some variation of its expression profile. Then, MIWI2 is expressed from $14.5 \mathrm{dpc}$ to $3 \mathrm{dpp}$, a short window of male germ line development during which de novo DNA methylation occurs. MIWI2 is also involved in the establishment of a repressive chromatin state around these regions [77-79]. MILI and MIWI2 act both together and independently [80]. Since MILI or MIWI2 deficiency leads to a major TE derepression, it is proposed that demethylation during fetal germ cell formation leads to a relaxation of TEs, the transcripts of which will fuel the piRNA pathway using MILI 
and MIWI2 as main actors and increase the production of piRNAs [50,51,77,78]. The same mechanism seems to act in human fetal male germ cells, where elevated TE expression is detected and associated with a high expression of genes involved in the piRNA pathway [81].

After 3 dpp, MIWI2 ceases to be expressed and MILI is the only protein of the piRNA pathway still present. At preleptotene, its expression decreases to reach an undetectable level at pachytene (7 dpp to $12 \mathrm{dpp}$ ) [56]. Then, its expression increases again and remains stable until round spermatid. The third mouse PIWI protein, MIWI, is then expressed from pachytene stage to elongated spermatid (10 dpp to $30 \mathrm{dpp}$ ) [78]. A novel class of piRNAs, named pachytene piRNAs, is detected. The latter maps to unique sites in the genome with few exceptions for some repeated TEs suggesting that the main role of pachytene piRNAs is not to silence TEs [48,82].

Overall, studies performed in mammals point out that TE transcripts resulting from a loss of DNA methylation, specific epigenetic reprogramming, or weakness in the piRNA pathway during a short window of time may be used by the germline to i) increase piRNA production, which in turn re-establishes a tight silencing of TEs later on in the development; and ii) participate in gene regulation, orchestrating early development.

\subsection{Weakness in the piRNA Pathway within the Dividing Cysts of Drosophila melanogaster Ovaries}

In drosophila, primordial germ cells (PGCs) are the first cells that are cellularized in the syncytial embryo at its posterior pole. At the blastoderm stage ( $3.5 \mathrm{~h}$ post-fertilization), these cells stop mitosis in G2 of the cell cycle. Around embryonic stage 10, PGCs migrate, split into two groups, and coalesce with somatic gonadal precursor cells to form two gonads. In females, PGCs proliferate all along the larval stage to reach around 100 cells at the 3rd larval stage. In pupal ovaries, PGCs are in contact with somatic niche cells (called cap cells). In adult females, ovaries are formed by 15 to 16 structures called ovarioles that have two to three germline stem cells (GSCs) at their anterior pole which divide asymmetrically to produce a GSC and a cystoblast. The cystoblast will undergo four rounds of mitosis with incomplete cytokinesis to form a 16-cell germline cyst. This happens in the anterior part of the ovarioles, in a structure called germarium. GSCs divide continuously, pushing cysts posteriorly [83]. When the cysts of 16 interconnected cells move to the posterior of the germarium, one of them begins its differentiation into an oocyte. It initiates meiosis and arrests at prophase I until stage 13. The 16-cell cysts are then surrounded by somatic cells to give rise to the first egg chamber of the ovariole [84]. At stage 13, the oocyte progresses to metaphase I and arrests again at stage 14. Meiosis completion occurs during egg activation following fertilization.

Numerous studies performed on Drosophila TEs in the germline have reported that many of them have the capacity to be transcribed in this lineage, but their activity is blocked both at the transcriptional and post-transcriptional level by the piRNA pathway. Could this silencing be relaxed sometimes to allow some replication cycle to occur? Little is known about relaxation of TE silencing during embryonic, larval, and pupal development of Drosophila. Marie and Ronsseray reported that the P-element silencing may be occasionally relaxed due to an incomplete silencing established in the embryonic germ cells and stably maintained throughout development [85]. Besides such occasional and early TE derepression, it has been reported that a spatiotemporal window exists in the dividing cysts of adult ovaries during which TEs can escape from host silencing (Figure 2). A detailed analysis of the repression exerted on Idefix- and P-element-sensor transgenes along oogenesis indeed revealed that their repression is partially released within the germarium when the cystoblast undergoes mitotic divisions to form the interconnected 16-cell germline cyst [86]. Among the major factors required for the piRNA pathway, aubergine (aub) and ago3 are both constantly expressed in the germline, including in the dividing cysts. Only piwi is poorly expressed in these germ cells, whereas its expression is clearly detected before and after mitotic cysts, in the GSC, in the cystoblast, and then from germarium 16-cell cysts to later stages. This spatiotemporal window during germline formation has been named the "PiwiLess Pocket" (Pilp). The specific lack of Piwi during this spatiotemporal window of drosophila germ cells is sufficient to allow TE transcription [87-89]. 


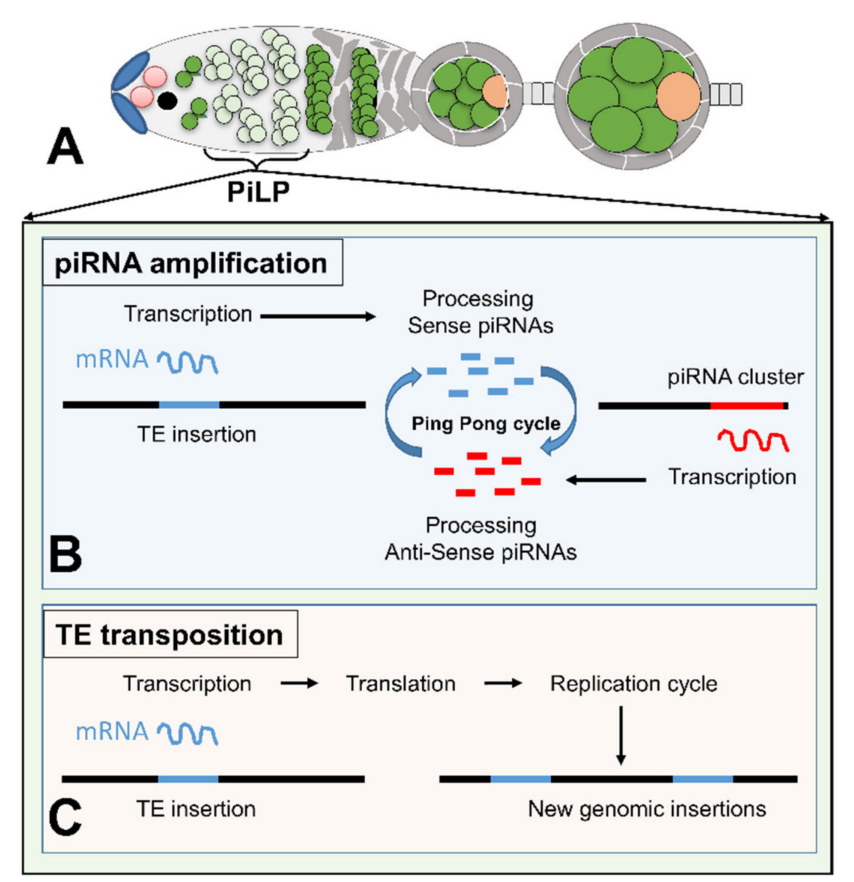

Figure 2. Model of the functional role of the "PiwiLess Pocket" (Pilp). (A) Schematic structure of a germarium and early egg chambers. Germline stem cells are in pink, the cystoblast in black, germ cells of the dividing cysts and nurse cells of the egg chambers in green with the Pilp indicated in light green, and the oocyte is in orange. The germinal cells are surrounded by somatic follicular cells (grey). (B) In the Pilp, TE transcripts resulting from a decrease of Piwi are processed into piRNAs that boost the ping-pong cycle through their complementarity to transcripts produced from piRNAs clusters (red). (C) In the Pilp, TE transcripts engage TEs in a new replication cycle leading to de novo genomic insertions.

PIWI proteins have been reported to play a crucial role in germ cell specification and differentiation during early development. In Drosophila, removal of maternal PIWI affects germ cell specification by affecting the maintenance of pole plasm [87]. The existence of the Pilp is then puzzling and raises the question as to the consequences of such a piRNA pathway weakness on germline development. On both the host and TE point of view, dividing cysts are a very suitable stage for mobilizations (Figure 2). Their germline origin ensures that the new genomic insertions will be transmitted to the next generation. Whenever the mobilization is high and/or lethal for the future embryo, the mutational events will be narrowed to a cyst and the germinal stem cell will keep its potential to produce new nonmutated cysts [88]. Moreover, the production of TE transcripts may be useful to fuel the ping-pong cycle and promote piRNA amplification thanks to Aub and Ago3 that are correctly expressed in the Pilp [89]. Interestingly, this can be considered as a strategy of the host allowing TE transcription to better repress these mutagenic agents for the rest of the developing germline and future embryo (Figure 2).

\subsection{Genes Responsible for Defense Against TEs Are Downregulated in the Vegetative Nucleus of Flowering Plants}

Cell-specific bursts of TE transcriptional activity in a wildtype background of epigenetically silenced TEs are reported in Arabidopsis, maize, and rice pollen. It is named DRTS for Developmental Relaxation of TE Silencing. In Arabidopsis, the DRTS occurs in the vegetative nuclei (VN). Unlike animals, where the germline is established during early embryogenesis, plant sexual reproduction initiates with the formation of meiotic competent cells in adults. The pollen mother cell undergoes meiosis to give rise to four products of meiosis that each undergo two mitotic divisions. The first division is highly asymmetric and forms a binucleate pollen grain with a larger vegetative cell and 
a smaller germ cell (GC). The second division is performed by the small germ cell and leads to a pair of sperm cells (SCs). At the point of release from the anthers, mature pollen grains of Arabidopsis thaliana contain three germ cells of distinct cell type: two identical germ cells providing the paternal DNA inheritance to the zygote and the endosperm. The vegetative nucleus does not contribute to the zygotic DNA, but it controls the delivery of sperm. Its DNA is in a decondensed state compared to the compact sperm nuclei [90].

Although an epigenetic silencing represses TEs throughout most plant development, a transient reactivation of TEs has been found in mature pollen of flowering plants. In Arabidopsis thaliana, both expression and transposition only occur in the $\mathrm{VN}$ and is correlated with a lack of chromatin remodeling ATPase Decrease in DNA Methylation 1 (DDM1), one of the main actors involved in TE silencing throughout plant development and found accumulated in the SCs [91]. It was further found that euchromatic TEs in the pollen VN undergo DEMETER-dependent DNA demethylation [92].

Differing from animal piRNAs, two types of plant gametophytic small RNAs assure repression of TEs and transgenerational inheritance of heterochromatin identity. Together with the RNA-directed DNA methylation (RdDM) pathway, 24-nt long RNAs assure TE transcriptional silencing (TGS). If reactivated, TEs can produce 21/22-nt long RNAs that assure a post-transcriptional silencing (PTGS) or, if loaded onto AGO6, also direct TGS [93]. A careful analysis of the mature sperm indicated that 24-nt small RNAs are lacking whereas 21-nt RNAs dramatically increase for several TEs.

Substantial knowledge gaps remain to be filled to fully appreciate the functional role of these small RNAs during the epigenetic reprogramming that has been observed in Arabidopsis meiocytes, endosperm, and nurse cells of gametophytes. Despite its potential danger, this cell-type specific epigenetic reprogramming could serve as a mechanism revealing TE presence to the germline, ensuring their control after fertilization. The 21-nt small RNAs accumulate in the VN and can migrate to the associated SC to reinforce silencing (Figure 3) [94]. Supporting that the DRTS function in companion cells is to reinforce TE silencing in gametes, depletion of the demethylase DEMETER in the VN not only leads to an increase of DNA methylation in the $\mathrm{VN}$, but also to a reduced methylation of TEs in the sperm cells. Overall, these data indicate that the very strict reactivation of TEs in the VN contributes to transgenerational TE silencing [92].

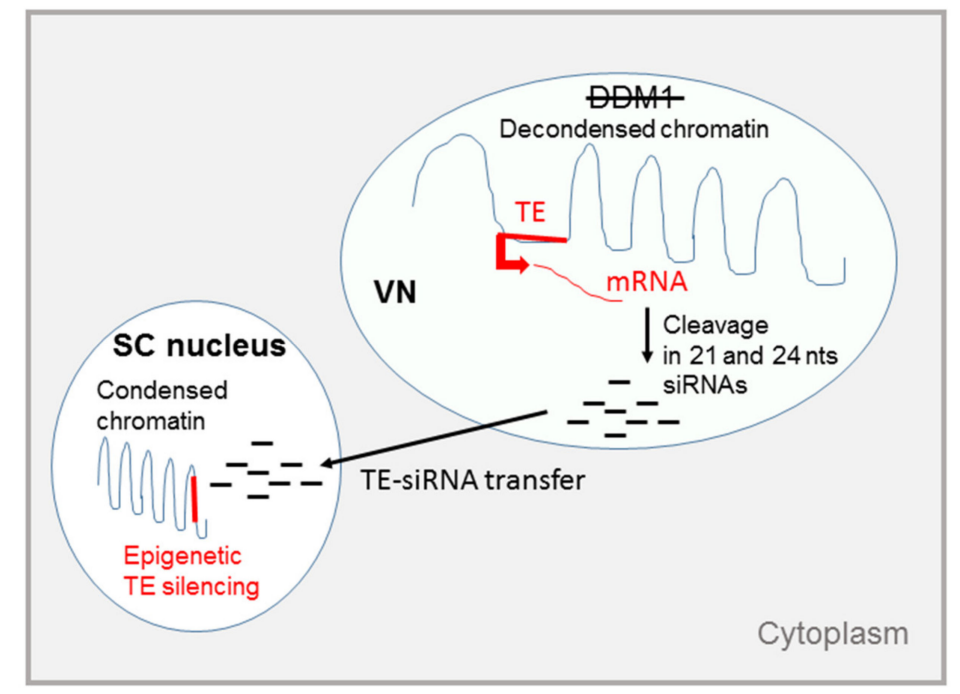

Figure 3. The potential role of siRNAs in the Arabidopsis male gametophyte. In the VN, the chromatin is in a decondensed state due to a lack of the chromatin remodeling protein DDM1. The transcription of TEs is allowed and gives rise to mRNAs that are cleaved in 21- and 24-nt siRNAs. These siRNAs may get out of the VN and enter the neighboring sperm cell where they direct DNA methylation of complementary TEs or genes. DNA is in blue, TEs and their mRNAs are in red. Cell-to-cell movement is indicated by an arrow. 
In addition to this, the potential role of DRTS could be to help TEs to evade long-term heterochromatic silencing. Releasing their silencing offers TEs the opportunity to start the replication cycle. Finally, although specific to TE-silencing and heterochromatin maintenance, a role of DRTS in regulating specific genes important in plant development has also been envisioned. In support of this, the endosperm-imprinted genes required for seed development are sensitive to TE activity [95].

\section{Conclusions}

A tight silencing of TEs is exerted through multiple and complementary mechanisms involving DNA methylation, transcriptional repressors, or small RNA production. However, TE-epigenetic transcriptional derepression occurs at specific stages during the normal development of wildtype organisms. In a selfish point of view, TEs could take this opportunity of chromatin reorganization required for cellular functions to transpose. However, this relaxation has been reported under strict developmental control in the germline of wildtype animals and plants, which rather suggests a programmed TE reactivation playing a functional role. The mechanisms allowing developmental precision of TE desilencing are just being elucidated. It is hard to estimate yet the significance and importance of this reactivation. However, host genes and TEs could share a mutual interest of such releases of control. Several examples are reported in this review, but one can anticipate that the list is far to be exhaustive. These TE reactivations during germline development add a new level of complexity in the relationship between TEs and their host genome and its potential trans-generational impact.

Author Contributions: Writing, S.M.-M. and C.V.; Supervision, C.V. All authors have read and agreed to the published version of the manuscript.

Funding: This work was supported by the « Agence Nationale de la Recherche » (https://anr.fr) (ANR-17-CE12-0030 EpiTET to C.V.). This research is supported by the French government IDEX-ISITE initiative 16-IDEX-0001 (CAP20-25).

Acknowledgments: We thank A. Molaro, C. White, P. Arnaud and our team for useful comments.

Conflicts of Interest: The authors declare no conflict of interest.

\section{References}

1. Bourque, G.; Burns, K.H.; Gehring, M.; Gorbunova, V.; Seluanov, A.; Hammell, M.G.; Imbeault, M.; Izsvák, Z.; Levin, H.L.; Macfarlan, T.S.; et al. Ten things you should know about transposable elements. Genome Biol. 2018, 19, 199. [CrossRef] [PubMed]

2. Gnanakkan, V.P.; Jaffe, A.; Dai, L.; Fu, J.; Wheelan, S.J.; Levitsky, H.I.; Boeke, J.D.; Burns, K.H. TE-array-A high throughput tool to study transposon transcription. BMC Genom. 2013, 14, 869. [CrossRef] [PubMed]

3. Kunarso, G.; Chia, N.Y.; Jeyakani, J.; Hwang, C.; Lu, X.; Chan, Y.-S.; Ng, H.H.; Bourque, G. Transposable elements have rewired the core regulatory network of human embryonic stem cells. Nat. Genet. 2010, 42, 631-634. [CrossRef] [PubMed]

4. Thybert, D.; Roller, M.; Navarro, F.C.; Fiddes, I.; Streeter, I.; Feig, C.; Martin-Galvez, D.; Kolmogorov, M.; Janoušek, V.; Akanni, W.; et al. Repeat associated mechanisms of genome evolution and function revealed by the Mus caroli and Mus paharigenomes. Genome Res. 2018, 28, 448-459. [CrossRef] [PubMed]

5. Panaud, O. Horizontal transfers of transposable elements in eukaryotes: The flying genes. Comptes Rendus Biol. 2016, 339, 296-299. [CrossRef] [PubMed]

6. Peccoud, J.; Loiseau, V.; Cordaux, R.; Gilbert, C. Massive horizontal transfer of transposable elements in insects. Proc. Natl. Acad. Sci. USA USA 2017, 114, 4721-4726. [CrossRef]

7. Zanni, V.; Eymery, A.; Coiffet, M.; Zytnicki, M.; Luyten, I.; Quesneville, H.; Vaury, C.; Jensen, S. Distribution, evolution, and diversity of retrotransposons at the flamenco locus reflect the regulatory properties of piRNA clusters. Proc. Natl. Acad. Sci. USA 2013, 110, 19842-19847. [CrossRef]

8. Warren, I.A.; Naville, M.; Chalopin, M.; Levin, P.; Berger, C.S.; Galiana, D.; Volff, J.-N. Evolutionary impact of transposable elements on genomic diversity and lineage-specific innovation in vertebrates. Chromosom. Res. 2015, 23, 505-531. [CrossRef] 
9. Huang, S.; Tao, X.; Yuan, S.; Zhang, Y.; Li, P.; Beilinson, H.A.; Zhang, Y.; Yu, W.; Pontarotti, P.; Escriva, H.; et al. Discovery of an Active RAG Transposon Illuminates the Origins of V(D)J Recombination. Cell 2016, 166, 102-114. [CrossRef]

10. Maor, G.L.; Sorek, R.; Levanon, E.Y.; Paz, N.; Eisenberg, E.; Ast, G. RNA-editing-mediated exon evolution. Genome Biol. 2007, 8, R29. [CrossRef]

11. Zhang, X.H.-F.; Chasin, L.A. Comparison of multiple vertebrate genomes reveals the birth and evolution of human exons. Proc. Natl. Acad. Sci. USA 2006, 103, 13427-13432. [CrossRef] [PubMed]

12. Dupressoir, A.; Marceau, G.; Vernochet, C.; Bénit, L.; Kanellopoulos, C.; Sapin, V.; Heidmann, T. Syncytin-A and syncytin-B, two fusogenic placenta-specific murine envelope genes of retroviral origin conserved in Muridae. Proc. Natl. Acad. Sci. USA 2005, 102, 725-730. [CrossRef] [PubMed]

13. Levy, O.; Knisbacher, B.A.; Levanon, E.Y.; Havlin, S. Integrating networks and comparative genomics reveals retroelement proliferation dynamics in hominid genomes. Sci. Adv. 2017, 3, e1701256. [CrossRef] [PubMed]

14. Liu, N.; Lee, C.H.; Swigut, T.; Grow, E.; Gu, B.; Bassik, M.C.; Wysocka, J. Selective silencing of euchromatic L1s revealed by genome-wide screens for L1 regulators. Nature 2018, 553, 228-232. [CrossRef] [PubMed]

15. Brozovic, M.; Dantec, C.; Dardaillon, J.; Dauga, D.; Faure, E.; Gineste, M.; Louis, A.; Naville, M.; Nitta, K.R.; Piette, J.; et al. ANISEED 2017: extending the integrated ascidian database to the exploration and evolutionary comparison of genome-scale datasets. Nucleic Acids Res. 2017, 46, D718-D725. [CrossRef]

16. Ade, C.; Engel, A.; Deininger, P. Alu elements: an intrinsic source of human genome instability. Curr. Opin. Virol. 2013, 3, 639-645. [CrossRef]

17. Belancio, V.P.; Hedges, D.J.; Deininger, P. Mammalian non-LTR retrotransposons: For better or worse, in sickness and in health. Genome Res. 2008, 18, 343-358. [CrossRef]

18. Hurst, G.D.D.; Werren, J.H. The role of selfish genetic elements in eukaryotic evolution. Nat. Rev. Genet. 2001, 2, 597-606. [CrossRef]

19. McLaughlin, R.N.; Gable, J.T.; Wittkopp, C.J.; Emerman, M.; Malik, H.S. Conservation and Innovation of APOBEC3A Restriction Functions during Primate Evolution. Mol. Biol. Evol. 2016, 33, 1889-1901. [CrossRef]

20. Friedli, M.; Trono, D. The Developmental Control of Transposable Elements and the Evolution of Higher Species. Annu. Rev. Cell Dev. Biol. 2015, 31, 429-451. [CrossRef]

21. Bourc'His, D.; Bestor, T.H. Meiotic catastrophe and retrotransposon reactivation in male germ cells lacking Dnmt3L. Nature 2004, 431, 96-99. [CrossRef] [PubMed]

22. Barau, J.; Teissandier, A.; Zamudio, N.; Roy, S.; Nalesso, V.; Herault, Y.; Guillou, F.; Bourc'His, D. The DNA methyltransferase DNMT3C protects male germ cells from transposon activity. Science 2016, 354, 909-912. [CrossRef] [PubMed]

23. Moran, J.V.; E Holmes, S.; Naas, T.; DeBerardinis, R.J.; Boeke, J.D.; Kazazian, H.H., Jr. High Frequency Retrotransposition in Cultured Mammalian Cells. Cell 1996, 87, 917-927. [CrossRef]

24. Molaro, A.; Malik, H.S. Hide and seek: how chromatin-based pathways silence retroelements in the mammalian germline. Curr. Opin. Genet. Dev. 2016, 37, 51-58. [CrossRef]

25. Molaro, A.; Malik, H.S.; Bourc'His, D. OUP accepted manuscript. Mol. Biol. Evol. 2020. [CrossRef]

26. Zamudio, N.; Barau, J.; Teissandier, A.; Walter, M.; Borsos, M.; Servant, N.; Bourc'His, D. DNA methylation restrains transposons from adopting a chromatin signature permissive for meiotic recombination. Genes Dev. 2015, 29, 1256-1270. [CrossRef]

27. Singal, R.; Ferris, R.; Little, J.A.; Wang, S.Z.; Ginder, G.D. Methylation of the minimal promoter of an embryonic globin gene silences transcription in primary erythroid cells. Proc. Natl. Acad. Sci. USA 1997, 94, 13724-13729. [CrossRef]

28. Walsh, C.P.; Chaillet, J.R.; Bestor, T.H. Transcription of IAP endogenous retroviruses is constrained by cytosine methylation. Nat. Genet. 1998, 20, 116-117. [CrossRef]

29. Yoder, J.A.; Walsh, C.P.; Bestor, T.H. Cytosine methylation and the ecology of intragenomic parasites. Trends Genet. 1997, 13, 335-340. [CrossRef]

30. Imbeault, M.; Helleboid, P.-Y.; Trono, D. KRAB zinc-finger proteins contribute to the evolution of gene regulatory networks. Nature 2017, 543, 550-554. [CrossRef]

31. Ecco, G.; Imbeault, M.; Trono, D. KRAB zinc finger proteins. Development 2017, 144, 2719-2729. [CrossRef] [PubMed]

32. Yang, P.; Wang, Y.; Macfarlan, T.S. The Role of KRAB-ZFPs in Transposable Element Repression and Mammalian Evolution. Trends Genet. 2017, 33, 871-881. [CrossRef] [PubMed] 
33. Jin, S.; Choi, H.; Kwon, J.T.; Kim, J.; Jeong, J.; Kim, J.; Hong, S.H.; Cho, C. Identification of target genes for spermatogenic cell-specific KRAB transcription factor ZFP819 in a male germ cell line. Cell Biosci. 2017, 7, 4. [CrossRef] [PubMed]

34. Wolf, D.; Goff, S.P. TRIM28 Mediates Primer Binding Site-Targeted Silencing of Murine Leukemia Virus in Embryonic Cells. Cell 2007, 131, 46-57. [CrossRef] [PubMed]

35. Wolf, G.; Yang, P.; Füchtbauer, A.C.; Füchtbauer, E.-M.; Silva, A.M.; Park, C.; Wu, W.; Nielsen, A.L.; Pedersen, F.S.; Macfarlan, T.S. The KRAB zinc finger protein ZFP809 is required to initiate epigenetic silencing of endogenous retroviruses. Genes Dev. 2015, 29, 538-554. [CrossRef] [PubMed]

36. Jacobs, F.M.; Greenberg, D.; Nguyen, N.; Haeussler, M.; Ewing, A.D.; Katzman, S.; Paten, B.; Salama, S.R.; Haussler, D. An evolutionary arms race between KRAB zinc-finger genes ZNF91/93 and SVA/L1 retrotransposons. Nature 2014, 516, 242-245. [CrossRef] [PubMed]

37. Thomas, J.H.; Schneider, S. Coevolution of retroelements and tandem zinc finger genes. Genome Res. 2011, 21, 1800-1812. [CrossRef]

38. Ozata, D.M.; Gainetdinov, I.; Zoch, A.; O'Carroll, D.; Zamore, P. PIWI-interacting RNAs: small RNAs with big functions. Nat. Rev. Genet. 2018, 20, 89-108. [CrossRef]

39. Ghildiyal, M.; Zamore, P. Small silencing RNAs: an expanding universe. Nat. Rev. Genet. 2009, 10, 94-108. [CrossRef]

40. Brennecke, J.; Aravin, A.A.; Stark, A.; Dus, M.; Kellis, M.; Sachidanandam, R.; Hannon, G.J. Discrete Small RNA-Generating Loci as Master Regulators of Transposon Activity in Drosophila. Cell 2007, 128, 1089-1103. [CrossRef]

41. Goriaux, C.; Desset, S.; Renaud, Y.; Vaury, C.; Brasset, E. Transcriptional properties and splicing of the flamenco pi RNA cluster. EMBO Rep. 2014, 15, 411-418. [CrossRef] [PubMed]

42. Mohn, F.; Sienski, G.; Handler, D.; Brennecke, J. The Rhino-Deadlock-Cutoff Complex Licenses Noncanonical Transcription of Dual-Strand piRNA Clusters in Drosophila. Cell 2014, 157, 1364-1379. [CrossRef] [PubMed]

43. Chen, Y.-C.A.; Stuwe, E.; Luo, Y.; Ninova, M.; Le Thomas, A.; Rozhavskaya, E.; Li, S.; Vempati, S.; Laver, J.D.; Patel, D.J.; et al. Cutoff Suppresses RNA Polymerase II Termination to Ensure Expression of piRNA Precursors. Mol. Cell 2016, 63, 97-109. [CrossRef] [PubMed]

44. Andersen, P.R.; Tirián, L.; Vunjak, M.; Brennecke, J. A heterochromatin-dependent transcription machinery drives piRNA expression. Nature 2017, 549, 54-59. [CrossRef]

45. Elmaghraby, M.F.; Andersen, P.R.; Pühringer, F.; Hohmann, U.; Meixner, K.; Lendl, T.; Tirian, L.; Brennecke, J. A Heterochromatin-Specific RNA Export Pathway Facilitates piRNA Production. Cell 2019, 178, 964-979.e20. [CrossRef]

46. Wang, J.; Saxe, J.P.; Tanaka, T.; Chuma, S.; Lin, H. Mili Interacts with Tudor Domain-Containing Protein 1 in Regulating Spermatogenesis. Curr. Biol. 2009, 19, 640-644. [CrossRef]

47. De Fazio, S.; Bartonicek, N.; Di Giacomo, M.; Abreu-Goodger, C.; Sankar, A.; Funaya, C.; Antony, C.; Moreira, P.N.; Enright, A.; O'Carroll, D. The endonuclease activity of Mili fuels piRNA amplification that silences LINE1 elements. Nature 2011, 480, 259-263. [CrossRef]

48. Reuter, M.; Berninger, P.; Chuma, S.; Shah, H.; Hosokawa, M.; Funaya, C.; Antony, C.; Sachidanandam, R.; Pillai, R.S. Miwi catalysis is required for piRNA amplification-independent LINE1 transposon silencing. Nature 2011, 480, 264-267. [CrossRef]

49. Aravin, A.; Gaidatzis, D.; Pfeffer, S.; Lagos-Quintana, M.; Landgraf, P.; Iovino, N.; Morris, P.; Brownstein, M.J.; Kuramochi-Miyagawa, S.; Nakano, T.; et al. A novel class of small RNAs bind to MILI protein in mouse testes. Nature 2006, 442, 203-207. [CrossRef]

50. Molaro, A.; Falciatori, I.; Hodges, E.; Aravin, A.A.; Marran, K.; Rafii, S.; McCombie, W.R.; Smith, A.D.; Hannon, G.J. Two waves of de novo methylation during mouse germ cell development. Genes Dev. 2014, 28, 1544-1549. [CrossRef]

51. Aravin, A.A.; Sachidanandam, R.; Bourc'His, D.; Schaefer, C.; Pezic, D.; Toth, K.F.; Bestor, T.; Hannon, G.J. A piRNA Pathway Primed by Individual Transposons Is Linked to De novo DNA Methylation in Mice. Mol. Cell 2008, 31, 785-799. [CrossRef] [PubMed]

52. Manakov, S.A.; Pezic, D.; Marinov, G.K.; Pastor, W.A.; Sachidanandam, R.; Aravin, A.A. MIWI2 and MILI Have Differential Effects on piRNA Biogenesis and DNA Methylation. Cell Rep. 2015, 12, 1234-1243. [CrossRef] [PubMed] 
53. Martens, J.H.A.; O'Sullivan, R.J.; Braunschweig, U.; Opravil, S.; Radolf, M.; Steinlein, P.; Jenuwein, T. The profile of repeat-associated histone lysine methylation states in the mouse epigenome. EMBO J. 2005, 24, 800-812. [CrossRef] [PubMed]

54. Kondo, Y.; Issa, J.-P. Enrichment for Histone H3 Lysine 9 Methylation at Alu Repeats in Human Cells. J. Biol. Chem. 2003, 278, 27658-27662. [CrossRef]

55. Mikkelsen, T.S.; Ku, M.; Jaffe, D.B.; Issac, B.; Lieberman, E.; Giannoukos, G.; Alvarez, P.; Brockman, W.; Kim, T.-K.; Koche, R.P.; et al. Genome-wide maps of chromatin state in pluripotent and lineage-committed cells. Nature 2007, 448, 553-560. [CrossRef]

56. Di Giacomo, M.; Comazzetto, S.; Saini, H.; De Fazio, S.; Carrieri, C.; Morgan, M.; Vasiliauskaite, L.; Benes, V.; Enright, A.; O'Carroll, D. Multiple Epigenetic Mechanisms and the piRNA Pathway Enforce LINE1 Silencing during Adult Spermatogenesis. Mol. Cell 2013, 50, 601-608. [CrossRef]

57. Castro-Díaz, N.; Ecco, G.; Coluccio, A.; Kapopoulou, A.; Yazdanpanah, B.; Friedli, M.; Duc, J.; Jang, S.M.; Turelli, P.; Trono, D. Evolutionally dynamic L1 regulation in embryonic stem cells. Genes Dev. 2014, 28, 1397-1409. [CrossRef]

58. Kurimoto, K.; Saitou, M. Germ cell reprogramming. Curr. Top. Dev. Biol. 2019, 135, 91-125. [CrossRef]

59. Dahl, J.A.; Jung, I.; Aanes, H.; Greggains, G.D.; Manaf, A.; Lerdrup, M.; Li, G.; Kuan, S.; Li, B.; Lee, A.Y.; et al. Broad histone H3K4me3 domains in mouse oocytes modulate maternal-to-zygotic transition. Nature 2016, 537, 548-552. [CrossRef]

60. Ancelin, K.; Syx, L.; Borensztein, M.; Ranisavljevic, N.; Vassilev, I.; Briseno-Roa, L.; Liu, T.; Metzger, E.; Servant, N.; Barillot, E.; et al. Maternal LSD1/KDM1A is an essential regulator of chromatin and transcription landscapes during zygotic genome activation. Elife 2016, 5, e08851. [CrossRef]

61. Smallwood, S.A.; Kelsey, G. De novo DNA methylation: a germ cell perspective. Trends Genet. 2012, 28, 33-42. [CrossRef] [PubMed]

62. Zhu, P.; Guo, H.; Ren, Y.; Hou, Y.; Dong, J.; Li, R.; Lian, Y.; Fan, X.; Hu, B.; Gao, Y.; et al. Single-cell DNA methylome sequencing of human preimplantation embryos. Nat. Genet. 2017, 50, 12-19. [CrossRef] [PubMed]

63. Evsikov, A.V.; De Vries, W.; Peaston, A.; Radford, E.; Fancher, K.; Chen, F.; A Blake, J.; Bult, C.; Latham, K.; Knowles, B.; et al. Systems biology of the 2-cell mouse embryo. Cytogenet. Genome Res. 2004, 105, $240-250$. [CrossRef] [PubMed]

64. Fadloun, A.; Le Gras, S.; Jost, B.; Ziegler-Birling, C.; Takahashi, H.; Gorab, E.; Carninci, P.; Torres-Padilla, M.-E. Chromatin signatures and retrotransposon profiling in mouse embryos reveal regulation of LINE-1 by RNA. Nat. Struct. Mol. Biol. 2013, 20, 332-338. [CrossRef] [PubMed]

65. Kigami, D.; Minami, N.; Takayama, H.; Imai, H. MuERV-L Is One of the Earliest Transcribed Genes in Mouse One-Cell Embryos1. Biol. Reprod. 2003, 68, 651-654. [CrossRef]

66. Percharde, M.; Lin, C.-J.; Yin, Y.; Guan, J.; Peixoto, G.A.; Bulut-Karslioglu, A.; Biechele, S.; Huang, B.; Shen, X.; Ramalho-Santos, M. A LINE1-Nucleolin Partnership Regulates Early Development and ESC Identity. Cell 2018, 174, 391-405.e19. [CrossRef]

67. Fu, B.; Ma, H.; Liu, D. Endogenous Retroviruses Function as Gene Expression Regulatory Elements During Mammalian Pre-implantation Embryo Development. Int. J. Mol. Sci. 2019, 20, 790. [CrossRef]

68. Beraldi, R.; Pittoggi, C.; Sciamanna, I.; Mattei, E.; Spadafora, C. Expression of LINE-1 retroposons is essential for murine preimplantation development. Mol. Reprod. Dev. 2006, 73, 279-287. [CrossRef]

69. Popp, C.; Dean, W.; Feng, S.; Cokus, S.J.; Andrews, S.; Pellegrini, M.; Jacobsen, S.E.; Reik, W. Genome-wide erasure of DNA methylation in mouse primordial germ cells is affected by AID deficiency. Nature 2010, 463, 1101-1105. [CrossRef]

70. Seisenberger, S.; Andrews, S.; Krueger, F.; Arand, J.; Walter, J.; Santos, F.; Popp, C.; Thienpont, B.; Dean, W.; Reik, W. The Dynamics of Genome-wide DNA Methylation Reprogramming in Mouse Primordial Germ Cells. Mol. Cell 2012, 48, 849-862. [CrossRef]

71. Kobayashi, H.; Sakurai, T.; Miura, F.; Imai, M.; Mochiduki, K.; Yanagisawa, E.; Sakashita, A.; Wakai, T.; Suzuki, Y.; Ito, T.; et al. High-resolution DNA methylome analysis of primordial germ cells identifies gender-specific reprogramming in mice. Genome Res. 2013, 23, 616-627. [CrossRef] [PubMed]

72. Malki, S.; Van Der Heijden, G.; O’Donnell, K.A.; Martin, S.L.; Bortvin, A. A role for retrotransposon LINE-1 in fetal oocyte attrition in mice. Dev. Cell 2014, 29, 521-533. [CrossRef] [PubMed] 
73. De La Fuente, R.; Baumann, C.; Fan, T.; Schmidtmann, A.; Dobrinski, I.; Muegge, K. Lsh is required for meiotic chromosome synapsis and retrotransposon silencing in female germ cells. Nature 2006, 8, 1448-1454. [CrossRef] [PubMed]

74. Lim, A.K.; Lorthongpanich, C.; Chew, T.G.; Tan, C.W.G.; Shue, Y.T.; Balu, S.; Gounko, N.V.; Kuramochi-Miyagawa, S.; Matzuk, M.M.; Chuma, S.; et al. The nuage mediates retrotransposon silencing in mouse primordial ovarian follicles. Development 2013, 140, 3819-3825. [CrossRef]

75. Van Der Heijden, G.; Bortvin, A. Transient relaxation of transposon silencing at the onset of mammalian meiosis. Epigenetics 2009, 4, 76-79. [CrossRef]

76. Clatterbuck-Soper, S.F.; Van Der Heijden, G.; Hardiman, T.C.; Goodheart, M.; Martin, S.L.; De Boer, P.; Bortvin, A. Mouse Maelstrom, a Component of Nuage, Is Essential for Spermatogenesis and Transposon Repression in Meiosis. Dev. Cell 2008, 15, 285-297. [CrossRef]

77. Carmell, M.A.; Girard, A.; Van De Kant, H.J.; Bourc'His, D.; Bestor, T.H.; De Rooij, D.G.; Hannon, G.J. MIWI2 Is Essential for Spermatogenesis and Repression of Transposons in the Mouse Male Germline. Dev. Cell 2007, 12, 503-514. [CrossRef]

78. Kuramochi-Miyagawa, S.; Kimura, T.; Ijiri, T.W.; Isobe, T.; Asada, N.; Fujita, Y.; Ikawa, M.; Iwai, N.; Okabe, M.; Deng, W.; et al. Mili, a mammalian member of piwi family gene, is essential for spermatogenesis. Development 2004, 131, 839-849. [CrossRef]

79. Pezic, D.; Manakov, S.A.; Sachidanandam, R.; Aravin, A.A. piRNA pathway targets active LINE1 elements to establish the repressive H3K9me3 mark in germ cells. Genes Dev. 2014, 28, 1410-1428. [CrossRef]

80. Vasiliauskaitè, L.; Vitsios, D.; Berrens, R.; Carrieri, C.; Reik, W.; Enright, A.; O'Carroll, D.; Vasilauskaitè, L. A MILI-independent piRNA biogenesis pathway empowers partial germline reprogramming. Nat. Struct. Mol. Biol. 2017, 24, 604-606. [CrossRef]

81. Reznik, B.; Cincotta, S.A.; Jaszczak, R.G.; Mateo, L.J.; Shen, J.; Cao, M.; Baskin, L.; Ye, P.; An, W.; Laird, D.J. Heterogeneity of transposon expression and activation of the repressive network in human fetal germ cells. Development 2019, 146, dev171157. [CrossRef]

82. Girard, A.; Sachidanandam, R.; Hannon, G.J.; Carmell, M.A. A germline-specific class of small RNAs binds mammalian Piwi proteins. Nature 2006, 442, 199-202. [CrossRef]

83. Williamson, A.; Lehmann, R. Germ Cell Development Indrosophila. Annu. Rev. Cell Dev. Biol. 1996, 12, 365-391. [CrossRef]

84. Huynh, J.-R.; Johnston, D.S. The Origin of Asymmetry: Early Polarisation of the Drosophila Germline Cyst and Oocyte. Curr. Biol. 2004, 14, R438-R449. [CrossRef]

85. Marie, P.P.; Ronsseray, S.; Boivin, A. From Embryo to Adult: piRNA-Mediated Silencing throughout Germline Development in Drosophila. G3: Genes|Genomes|Genetics 2016, 7, 505-516. [CrossRef]

86. Dufourt, J.; Dennis, C.; Boivin, A.; Gueguen, N.; Théron, E.; Goriaux, C.; Pouchin, P.; Ronsseray, S.; Brasset, E.; Vaury, C. Spatio-temporal requirements for transposable element piRNA-mediated silencing during Drosophila oogenesis. Nucleic Acids Res. 2013, 42, 2512-2524. [CrossRef]

87. Megosh, H.B.; Cox, D.N.; Campbell, C.; Lin, H. The Role of PIWI and the miRNA Machinery in Drosophila Germline Determination. Curr. Biol. 2006, 16, 1884-1894. [CrossRef]

88. Dufourt, J.; Vaury, C. During a short window of Drosophila oogenesis, piRNA biogenesis may be boosted and mobilization of transposable elements allowed. Front. Genet. 2014, 5, 385. [CrossRef] [PubMed]

89. Théron, E.; Maupetit-Mehouas, S.; Pouchin, P.; Baudet, L.; Brasset, E.; Vaury, C. The interplay between the Argonaute proteins Piwi and Aub within Drosophila germarium is critical for oogenesis, piRNA biogenesis and TE silencing. Nucleic Acids Res. 2018, 46, 10052-10065. [CrossRef] [PubMed]

90. Schmidt, A.; Schmid, K.J.; Grossniklaus, U. Plant germline formation: Common concepts and developmental flexibility in sexual and asexual reproduction. Development 2015, 142, 229-241. [CrossRef] [PubMed]

91. Slotkin, R.K.; Vaughn, M.W.; Borges, F.; Tanurdzic, M.; Becker, J.; Feijó, J.A.; Martienssen, R.A. Epigenetic Reprogramming and Small RNA Silencing of Transposable Elements in Pollen. Cell 2009, 136, 461-472. [CrossRef] [PubMed]

92. Ibarra, C.A.; Feng, X.; Schoft, V.; Hsieh, T.-F.; Uzawa, R.; Rodrigues, J.; Zemach, A.; Chumak, N.; Machlicova, A.; Nishimura, T;; et al. Active DNA Demethylation in Plant Companion Cells Reinforces Transposon Methylation in Gametes. Science 2012, 337, 1360-1364. [CrossRef] [PubMed] 
93. Creasey, K.M.; Zhai, J.; Borges, F.; Van Ex, F.; Regulski, M.; Meyers, B.C.; Martienssen, R.A. miRNAs trigger widespread epigenetically activated siRNAs from transposons in Arabidopsis. Nature 2014, 508, 411-415. [CrossRef] [PubMed]

94. Martinez, G.; Panda, K.; Köhler, C.; Slotkin, R.K. Silencing in sperm cells is directed by RNA movement from the surrounding nurse cell. Nat. Plants 2016, 2, 16030. [CrossRef] [PubMed]

95. Gehring, M.; Bubb, K.L.; Henikoff, S. Extensive Demethylation of Repetitive Elements During Seed Development Underlies Gene Imprinting. Science 2009, 324, 1447-1451. [CrossRef] [PubMed]

(C) 2020 by the authors. Licensee MDPI, Basel, Switzerland. This article is an open access article distributed under the terms and conditions of the Creative Commons Attribution (CC BY) license (http://creativecommons.org/licenses/by/4.0/). 